\title{
Material Dimensionality Effects on the Nanoindentation Behavior of Al/a-Si Core-Shell Nanostructures
}

\author{
Robert A. Fleming ${ }^{\text {a, b) }}$, Josue A. Goss ${ }^{\text {b) }}$, and Min Zou* a, b) \\ ${ }^{\text {a) }}$ Department of Mechanical Engineering, \\ b) Center for Advanced Surface Engineering \\ University of Arkansas, Fayetteville, AR 72701, USA
}

* To whom correspondence should be addressed. Tel: (479) 575-6671, Fax: (479) 575-6982, Email: mzou@uark.edu. 


\begin{abstract}
The nanoindentation behavior of hemispherical Al/a-Si core-shell nanostructures (CSNs), horizontally-aligned Al/a-Si core-shell nanorods (CSRs) with various lengths, and an Al/a-Si layered thin film has been studied to understand the effects of geometrical confinement of the Al core on the CSN deformation behavior. When loaded beyond the elastic limit, the CSNs have an unconventional load-displacement behavior with no residual displacement after unloading, resulting in no net shape change after indentation. This behavior is enabled by dislocation activities within the confined $\mathrm{Al}$ core, as indicated by discontinuous indentation signatures (loaddrops and load-jumps) observed in the load-displacement data. When the geometrical confinement of the core is slightly reduced, as in the case of CSRs with the shortest rod length, the discontinuous indentation signatures and deformation resistance are heavily reduced. Further decreases in core confinement result in conventional nanoindentation behavior, regardless of geometry. Supporting molecular dynamics simulations show that dislocations nucleated in the core of a CSN are more effectively removed during unloading compared to CSRs, which supports the hypothesis that the unique deformation resistance of Al/a-Si CSNs are enabled by 3dimensional confinement of the Al core.
\end{abstract}

Keywords: Core-shell nanostructure; nanoindentation; core confinement; dislocations; molecular dynamics. 


\section{Introduction}

It is well known that the mechanical properties of nanostructures and thin films can differ greatly from those of their bulk counterparts. As the critical dimension of these structures decreases below the sub-micron length scale, the mechanical behavior becomes much more dependent on the dynamics of the included dislocations, leading to a host of effects that are typically not observed in bulk materials. This includes not only the familiar Hall-Petch strengthening mechanism in nano-grained metals [1-3], but also more unusual material behaviors such as size effects [4-6], dislocation starvation [7,8], and mechanical annealing phenomena [9]. Utilizing these unique mechanical properties allows for the design and fabrication of engineered nanostructures and surfaces that can potentially benefit a number of micro- and nanomechanical applications.

Currently, nanostructures are seldom used in applications that rely on significant contact interactions. Due to the nanoscale sizes of these materials and the resulting small contact areas, very high contact pressures can be generated, resulting in permanent plastic deformation of the nanostructures at even the moderate loads experienced in micro- and nano-systems. However, as a potential solution to this issue, deformation-resistant behavior has been identified in several different nanomaterials. Reverse plastic strains in response to compression loading have been observed in pristine, single-crystal Si nanospheres [10,11], which were attributed to dislocations retracing their paths and annihilating during unloading. $\mathrm{CoB}_{2} / \mathrm{SiO}_{2}$ core-shell nanostructures have been shown to also exhibit similar reverse plasticity [12,13]. In both materials, the deformation recovery is typically incomplete and is limited to small deformations. Notably, complete deformation resistance has been demonstrated in certain core/shell materials. $\mathrm{Ag} / \mathrm{SiO}_{2}$ 
core-shell nanowires have been shown to have enhanced fracture resistance and nearly complete shape restoration after bending deformation, even up to bending deflections approaching $90^{\circ}$ [14]. This behavior was only observed in the core-shell nanowires, and not in identically prepared $\mathrm{Ag}$ nanowires and hollow $\mathrm{SiO}_{2}$ nanotubes, which indicates that this behavior is explicitly tied to the core-shell structure.

$\mathrm{Al} / \mathrm{a}-\mathrm{Si}$ core-shell nanostructures (CSNs), composed of a nanotextured $\mathrm{Al}$ thin film coated with a conformal shell of a-Si, have also been shown to have deformation resistant properties [15]. When loaded beyond the elastic limit, the CSNs have an unconventional load-displacement behavior with no residual displacement after unloading, resulting in no net shape change after indentation. This was theorized to be the result of confinement of the soft $\mathrm{Al}$ core within the hard a-Si shell. Furthermore, surfaces textured with these CSNs are found to have superior tribological and deformation-resistant properties compared to Al nanodots and single-crystal $\mathrm{Si}$ [16]. When subjected to nanoscratch testing with a $100 \mu \mathrm{m}$ diamond tip, the CSN-textured surfaces had both a lower coefficient of friction and no observable surface deformation, even for contact loads as high as $8000 \mu \mathrm{N}$.

The idea that material "dimensionality" can affect the mechanical behavior of materials with sub-micron dimensions was studied by Mordehai et al., who performed indentation experiments on several different $\mathrm{Au}$ nanomaterials, including symmetric single-crystal nanoparticles, laterally-elongated nanostructures, and thin films [17]. They found that the mechanical behavior of the nanoparticles was dominated by dislocation annihilation events at the free surfaces of the nanoparticles, while indentation of the thin films resulted in dislocation pile-up beneath the 
indenter. Furthermore, the laterally-elongated structures exhibited an intermediate behavior, due to competition between dislocation annihilation at free surfaces and the formation of sessile dislocation structures.

With this knowledge that material dimensionality can affect the mechanical behavior of smallscale structures, it is therefore of interest to determine how changes in the dimensionality of the Al core will influence the deformation resistant properties of $\mathrm{Al} / \mathrm{a}-\mathrm{Si} \mathrm{CSNs}$. In this study, the role of geometric dimensionality on the mechanical behavior of several different geometries of nanostructures is assessed. Specifically, this includes hemispherical Al/a-Si CSNs, horizontallyaligned Al/a-Si core-shell nanorods (CSRs) of various lengths, and an Al/a-Si layered thin film, which represent 3-, 2-, and 1-dimensional confinement of the Al core, respectively. The results show that the hemispherical CSNs are deformation resistant, with nearly complete deformation recovery after indentation, even when loaded beyond the elastic limit. This deformation resistance is found to be enabled by the 3-dimensional confinement of the Al core in this structure. As this confinement is reduced, more conventional indentation behavior is observed with permanent residual deformation of the nanostructures.

\section{Experimental}

\subsection{Nanostructure Fabrication}

Patterned arrays of $\mathrm{Al}$ nanodots and horizontally-aligned Al nanorods were fabricated using electron beam lithography (EBL) and a metal lift-off procedure. First, a 4\% dilution of 495k MW PMMA (a positive tone electron resist) was spin coated onto a (100) single crystal Si wafer at $3000 \mathrm{rpm}$. An electron beam writer (JBX-9300FS, JEOL Ltd.) was used to selectively expose 
the electron resist using $1 \mathrm{nA}$ of current, a $50 \mathrm{kV}$ accelerating voltage, and a beam dose of 1000 $\mu \mathrm{C} / \mathrm{cm}^{2}$. After exposure, the sample was developed in a 1:3 mixture of methyl isobutyl ketone (MIBK) and isopropyl alcohol (IPA) for $45 \mathrm{~s}$, and then rinsed in pure IPA for 15 seconds, resulting in patterned arrays of holes in the PMMA film. Next, $100 \mathrm{~nm}$ of Al was deposited onto the patterned PMMA film using thermal evaporation (Auto 306D, Edwards Vacuum) with a deposition rate of $0.4 \mathrm{~nm} / \mathrm{s}$. Finally, the remaining PMMA was selectively removed by immersion in a Remover PG (MicroChem Corp.) bath heated to $75^{\circ} \mathrm{C}$ for 48 hours. The end result is patterned arrays of $\mathrm{Al}$ nanostructures (nanodots and horizontally-aligned nanorods) that are rigidly attached to the Si substrate. Using this fabrication method, hemispherical Al nanodots with $100 \mathrm{~nm}$ diameters and horizontally-aligned Al nanorods with diameters of $100 \mathrm{~nm}$ and lengths of $100 \mathrm{~nm}, 500 \mathrm{~nm}$, and $10 \mu \mathrm{m}$ were fabricated. A schematic of the rod geometry is shown in Fig. 1; note that the specified rod length excludes the hemispherical end-caps of each rod. A $100 \mathrm{~nm} \mathrm{Al} \mathrm{thin} \mathrm{film} \mathrm{was} \mathrm{also} \mathrm{fabricated} \mathrm{with} \mathrm{thermal} \mathrm{evaporation} \mathrm{using} \mathrm{the} \mathrm{same}$ deposition parameters as in the EBL procedure.

The patterned nanostructure arrays and Al thin film were then coated with $300 \mathrm{~nm}$ of a-Si using plasma enhanced chemical vapor deposition (PECVD; SLR730, Plasma-Therm). The substrate temperature, $\mathrm{rf}$ power, and silane flow rate were $250^{\circ} \mathrm{C}, 20 \mathrm{~W}$, and $85 \mathrm{sccm}$, respectively, during a-Si deposition. This results in 3 different geometries of $\mathrm{Al} / \mathrm{a}-\mathrm{Si}$ nanostructures, with different levels of core confinement: hemispherical CSNs, in which the Al core is axisymmetrically confined by the a-Si shell and by the Si substrate; CSRs, which have reduced core confinement along the longitudinal axis of the rod; and an Al/a-Si layered thin film, where the Al layer is only 
confined between the Si substrate and the a-Si film, with no lateral confinement. These 3 geometries are shown schematically in Fig. 2.

\subsection{Mechanical Characterization}

An instrumented nanoindenter (TriboIndenter, Hysitron) was used to characterize the mechanical behavior of the nanostructures, primarily using displacement-controlled indentation, which is more sensitive to transient events during indentation than load-controlled indentation [18]. The nanoindenter utilizes electrostatic force actuation and a capacitive displacement-sensing scheme, with a $3 \mathrm{nN}$ force resolution and a $0.02 \mathrm{~nm}$ displacement resolution, respectively. The structures

were indented with a feedback-controlled displacement rate of $3 \mathrm{~nm} / \mathrm{s}$ while simultaneously measuring the applied force, using a conical diamond tip of $1 \mu \mathrm{m}$ tip radius of curvature. A large tip radius, compared to a more conventional Berkovich indenter, was chosen to provide compression loading to the CSNs and CSRs, rather than indenting the structures.

The nanoscale surface topography and morphology of the nanostructures were characterized with a combination of scanning electron microscopy (SEM; Nova NanoLab, FEI), atomic force microscopy (AFM; Dimension Icon, Bruker), and an integrated scanning probe microscope (SPM) on the nanoindenter using the same $1 \mu \mathrm{m}$ tip.

\section{Results and Discussion}

\subsection{Nanostructure Morphology Characterization}

Using the EBL fabrication method, very uniform arrays of $\mathrm{Al}$ nanodots and nanorods were fabricated for the cores of the CSNs and CSRs, respectively. SEM micrographs of $100 \mathrm{~nm}$ 
diameter $\mathrm{Al}$ nanodots and $100 \mathrm{~nm}, 500 \mathrm{~nm}$, and $10 \mu \mathrm{m}$ Al nanorods are shown in Fig. 3. The Al nanostructures are polycrystalline, with a mixture of (111) and (200) crystallites, based on X-ray diffraction measurements of a similarly prepared Al thin film. Deposition of a-Si on these nanostructures results in a conformal shell on the nanostructures, as seen in SEM images in Fig. 4. Due to the conformal nature of the coating, the lateral dimensions of the visible portion of the individual nanostructures measured from the SEM images uniformly increases by $300 \mathrm{~nm}$ for both the CSNs and the CSRs, with only the top $\sim 100 \mathrm{~nm}$ of the structure protruding from the surface. The diameter of the CSNs increases to $400 \mathrm{~nm}$, while the width of the CSRs increases to $400 \mathrm{~nm}$, regardless of core length, and the length of the CSRs increases by $300 \mathrm{~nm}$ compared to the lengths of $\mathrm{Al}$ nanorods. Some small-scale roughness is evident in the shell morphology, as seen in the AFM images in Fig. 5, but since it is substantially smaller than the tip radius used during nanoindentation, it is not expected to interfere with the mechanical characterization.

\subsection{Nanoindentation Measurements}

\subsubsection{Deformation Resistant CSNs}

Nanoindentation experiments were performed to characterize the mechanical response of hemispherical CSNs to compression loading. Several different types of mechanical response are observed as function of indentation depth, as can be seen from load-displacement curves for 20 , 40, 60, and $80 \mathrm{~nm}$ displacement-controlled indentations in Fig. 6. The $20 \mathrm{~nm}$ indentation has an indentation response that is either elastic or a small hysteresis loop, which indicates that this displacement is at or just beyond the elastic limit of the CSN. The $40 \mathrm{~nm}$ indentation has a smooth loading curve, as well as a smooth unloading curve with a slope inflection that brings the indenter displacement back to zero. At the highest indentation displacements of 60 and $80 \mathrm{~nm}$, a 
large number of discontinuous indentation signatures, called load-drops and load-jumps, are evident during loading and unloading, respectively, as well as a slope inflection during unloading similar to that seen in the $40 \mathrm{~nm}$ indent. As can be seen, the indenter displacement returns to zero (or nearly to zero) regardless of the applied maximum indenter displacement, which indicates that very little residual deformation remains after indentation. In light of the fact that for the $80 \mathrm{~nm}$ indents, the maximum indentation depth is $20 \%$ of the total structure height of 400 $\mathrm{nm}$, this deformation resistance is especially notable and is consistent with previously reported measurements on $\mathrm{Al} / \mathrm{a}-\mathrm{Si}$ nanostructures fabricated from a nanotextured $\mathrm{Al}$ thin film $[15,16]$.

The observed indentation signatures correspond to micro- or nanoscale events happening beneath the indenter tip and are analogous to the pop-in/pop-out events commonly seen in loadcontrolled nanoindentation experiments. The origin of these signatures depends heavily on the type of material being investigated and can be the result of a variety of distinct mechanisms, including dislocation nucleation and propagation events in metals $[19,20]$, phase transformations in semiconductors [21], cracking in brittle materials [22], and thin film delamination [23]. However, the latter three mechanisms can be discounted as a potential source of the indentation signatures observed in Al/a-Si CSNs. Multiple repeated indents on individual CSNs show consistent hardening behavior after each subsequent indent, as shown in Fig. 7 for $80 \mathrm{~nm}$ displacement-controlled indents, which precludes both cracking of the a-Si film or delamination at the $\mathrm{Al} / \mathrm{a}-\mathrm{Si}$ interface as the source of the indentation signatures. If such cracking or delamination occurred, subsequent indents would result in further crack growth or delamination, which would elicit a weakened response in the CSNs. This conclusion is further supported by high resolution SEM images of focused ion beam (FIB) milled cross-sections of an unindented 
CSN and a CSN that has been subjected to 4 sequential $1000 \mu \mathrm{N}$ load-controlled indentations, shown in Fig. 8. In comparison to the unindented CSN, the apex of the indented nanostructure is slightly flattened; however, it should be noted this CSN was indented to almost twice the maximum contact load than the CSN characterized in Fig. 7. Even at this much larger contact load, no evidence of shell delamination or crack formation is observed. In addition, nanoindentation experiments on a smooth a-Si thin film showed no evidence of a pressureinduced phase transformation up to an estimated contact pressure of $\sim 22 \mathrm{GPa}$.

Since shell fracture, shell delamination, and a-Si phase transformations have all been eliminated as potential sources of the indentation signatures seen in the load-displacement curves, this strongly suggests that dislocation activities within the $\mathrm{Al}$ core are responsible. The hardening behavior that is observed upon repeated indentation further suggests that dislocations play a significant role in the mechanical behavior of CSNs, as it is consistent with strain hardening. It is hypothesized that the 3-dimensional confinement of the Al core in the hemispherical CSNs creates conditions that are favorable to allow dislocations that are generated in the $\mathrm{Al}$ core during loading to retrace their paths or otherwise annihilate during unloading. Structures with reduced core confinement, namely horizontally aligned CSRs and layered thin films, should display different mechanical behavior as the core confinement is decreased.

\subsubsection{Effects of Decreased Core Confinement}

Nanoindentation experiments were conducted on CSRs with a core length of $100 \mathrm{~nm}$ to test this hypothesis. The elongated core of this structure breaks the axisymmetric core confinement of the CSNs, which we define as 2-dimensional core confinement due to the additional core volume 
along the longitudinal axis of the rod. A load-displacement curve for an $80 \mathrm{~nm}$ displacementcontrolled indentation on a CSR is shown in Fig. 9, along with an AFM image of the structure morphology after indentation. The load signatures seen in the load-displacement data of the CSNs are still evident in the CSR, but the number and magnitude are significantly changed. For example, in the $80 \mathrm{~nm}$ indent in Fig. 6, approximately 9 load-drops and 8 load jumps are observed, with average magnitudes of $13.7 \mu \mathrm{N}$ and $10.7 \mu \mathrm{N}$, respectively. In comparison, approximately 4 load-drops and 5 load-jumps are seen in Fig. 9(b), with the indentation signature populations dominated by a single, large magnitude signature, along with several much smaller secondary load signatures. During loading, a large load-drop with a magnitude of $63.2 \mu \mathrm{N}$ occurs near the maximum indenter displacement, as well as 3 other load-drops with an average magnitude of $1.5 \mu \mathrm{N}$. Similarly, during unloading, a $30.2 \mu \mathrm{N}$ load-jump occurs in addition to 4 other load-jumps with an average magnitude of $9.4 \mu \mathrm{N}$. In addition, the indenter displacement no longer returns to zero during unloading and residual deformation of the structure is clearly seen from the AFM image, meaning that the CSRs are not deformation resistant.

Multiple repeated indents on a single CSR results in an increase in maximum indentation load after each indentation, as seen in the load-displacement curves for 4 sequential indents on a CSR in Fig. 10. Although this behavior was attributed to strain hardening in the CSNs, the residual deformation on the CSRs after indentation (Fig. 9(b)) results in an increase in contact area for each subsequent indentation, which can also explain the increase in maximum indentation load for multiple indentations. Even so, the presence of load-drops and load-jumps suggests that dislocations activities within the confined $\mathrm{Al}$ core of the CSR still play a key role on the mechanical behavior, but the reduced confinement perhaps inhibits the ability of dislocations to 
annihilate during unloading. To further explore this, nanoindentation experiments were also performed on CSRs with core lengths of $500 \mathrm{~nm}$ and $10 \mu \mathrm{m}$, as well as an Al/a-Si thin film. Representative load-displacement curves for $80 \mathrm{~nm}$ displacement-controlled indents on all 5 geometries, including the hemispherical CSNs and the $100 \mathrm{~nm}$ CSRs, are shown in Fig. 11. As previously noted, the CSN has an unconventional mechanical response characterized by numerous discontinuous indentation signatures and deformation-resistant behavior as indicated by zero residual displacement after unloading. When the confinement of the Al core is slightly reduced, as in the $100 \mathrm{~nm}$ CSR, the number and magnitude of the observed indentation signatures are heavily reduced, along with the deformation resistance. As the core confinement is reduced further, however, there is a sharp transition in the mechanical behavior. The $500 \mathrm{~nm}$ and $10 \mu \mathrm{m}$ CSRs, as well as the layered thin film, all have a more conventional loaddisplacement response, with no indentation signatures observed during loading and unloading and a substantial residual displacement evident in the load-displacement curve. This residual displacement accompanies the residual impressions left on the structures after indentation, as shown in SPM images in Fig. 12.

Analysis of the contact stiffness provides further insights into the mechanical behavior of these structures. A plot of contact stiffness vs. maximum indentation depth for all 5 geometries is shown in Fig. 13. For the CSNs, the contact stiffness increases with indentation depth up to 60 $\mathrm{nm}$, at which point it becomes practically constant. Combined with the CSN load-displacement curves in Fig. 6, this trend provides information about the evolution of the indentation response of the CSNs with increasing indentation depth. For the $20 \mathrm{~nm}$ indents, where the CSNs behave elastically, the indenter is only interacting with the a-Si shell due to the thickness of the shell and 
the shallow depth of the indent. When the indentation depth increases to $40 \mathrm{~nm}$, the contact stiffness increases as the Al core begins to be elastically compressed between the a-Si shell and the Si substrate. During unloading, this elastic recovery coincides with the slope inflection that is observed in the load-displacement data. At 60 and $80 \mathrm{~nm}$ indentation depths, the contact stiffness reaches a maximum value that is largely independent of indentation depth. At these depths, the Al core begins to be plastically deformed, resulting in the nucleation and propagation of dislocations which are evident by the load-drops and load-jumps during loading and unloading, respectively. Similar contact stiffness behavior is also observed in the $100 \mathrm{~nm}$ CSRs, which also show some evidence of dislocation activities during indentation, as noted in Fig. 9 and Fig. 10.

The contact stiffnesses of the $500 \mathrm{~nm}$ CSRs, $10 \mu \mathrm{m}$ CSRs, and layered thin film, however, all increase linearly with indentation depth, with values that generally overlap. In effect, the longer CSRs have a mechanical response that is largely indistinguishable from that of the layered thin film geometry. Moreover, the transition from the deformation-resistant behavior in the CSNs to the conventional indentation behavior of the layered thin films occurs abruptly, i.e., when the 3dimensional core confinement of the CSN is reduced slightly, as in the $100 \mathrm{~nm} \mathrm{CSR}$, the deformation resistance and the accompanying indentation signatures are heavily reduced. More drastic reductions in core confinement result in a conventional indentation response, regardless of the dimensionality of the core confinement. As a result, it is very clear that 3-dimensional core confinement plays a critical role in the novel deformation-resistant behavior of $\mathrm{Al} / \mathrm{a}-\mathrm{Si}$ CSNs. 


\subsection{Molecular Dynamics (MD) Simulations}

Supporting MD simulations using LAMMPS [24] were undertaken to further explore the role that core confinement plays on the dynamics of the dislocations nucleated during indention of these structures. The modified embedded atom method (MEAM) [25] was used to model all atomic interactions with a specialized $\mathrm{Al}-\mathrm{Si}$ interatomic potential [26]. The simulation domain consists of a single-crystal (001) FCC Al core covered by a shell of a-Si, shown schematically in Fig. 14. Prior to nanoindentation, the potential energy of the system was minimized using a conjugate gradient method with a relative energy tolerance of $10^{-6}$, followed by equilibration to $300 \mathrm{~K}$ using a Nosé-Hoover thermostat for 30,000 time steps with a time step of $1 \mathrm{fs}$. The a-Si shell was constructed by randomly populating the shell region with $\mathrm{Si}$ atoms and then systemically removing atoms that are too close together in order to achieve an equilibrium shell density of $2.28 \mathrm{~g} / \mathrm{cm}^{3}$, which is the measured density of a-Si [27].

\subsubsection{Nanoindentation Simulations and Dislocation Density Calculations}

Nanoindentation simulations were performed on several different geometries of $\mathrm{Al} / \mathrm{a}-\mathrm{Si}$ nanostructures: a CSN with a $15 \mathrm{~nm}$ core radius and CSRs with a rod radius of $15 \mathrm{~nm}$ and core lengths of 15, 25, and $35 \mathrm{~nm}$, all with a $5 \mathrm{~nm}$ shell thickness. For these simulations, the indenter is modeled as a purely repulsive spherical potential with a radius of $100 \mathrm{~nm}$ and controlled to

move $6 \mathrm{~nm}$ into the nanostructure at a constant rate of $0.5 \AA / p s$ while maintaining a system temperature of $300 \mathrm{~K}$. After reaching the specified indenter displacement, the indenter is completely retracted at the same displacement rate. Dislocation activities within the Al core are characterized using the dislocation extraction algorithm (DXA) [28] within the Open Visualization Tool (OVITO) [29]. 
A snapshot of the atomic distortion resulting from dislocations nucleated in the core of a CSN at maximum indenter displacement is shown in Fig. 15(a). The core has been sliced down the middle to visualize an interior plain of atoms, which are colored by lattice structure. The green atoms are in a face-centered cubic (FCC) arrangement and the red atoms are hexagonal closepacked (HCP) atoms representing a stacking fault formed by the nucleation of Shockley partial dislocations. A more detailed view of the dislocation content is provided in Fig. 15(b), showing only the HCP atoms that primarily comprise the stacking faults, with the leading and trailing Shockley partials represented as green lines. As indicated, one pair of Shockley partials has cross-slipped into an adjacent slip plane. This cross-slipped dislocation structure is far less mobile than in-plane Shockley partial dislocations, which will potentially affect the dynamics of these dislocations after the removal of the applied indentation load. To visualize this, the time evolution of the dislocation content within the core is shown in Fig. 15(c), with all atoms removed to show only the dislocations within the interior of the core. The individual dislocation lines are colored by Burgers vector, with perfect FCC dislocations, Shockley partials, Hirth dislocations, and other dislocations colored blue, green, black, and red, respectively. As the nanostructure is indented, dislocations, consisting primarily of glissile Shockley partials, are nucleated at the core/shell interface and further propagate. This continues until a maximum dislocation density is reached at the maximum indenter displacement. During unloading, a notable egression of dislocations occurs as the mobile dislocations are reabsorbed by the core/shell interface. This continues even after the indenter loses contact with the CSN, eventually reaching an equilibrium dislocation density. A non-zero equilibrium dislocation density is typically due to the formation of sessile dislocation structures, either due to cross-slip 
(as demonstrated here) or other dislocation reactions. In this case, $\sim 93 \%$ of the dislocations nucleated during loading have been reabsorbed by the core/shell interface or otherwise annihilated. It should be noted that this phenomenon is specific to the core-shell structure, as similar simulations performed on Al nanodots result in stable dislocation densities that do not substantially decrease during unloading.

To characterize how the dimensionality of core confinement affects the behavior of dislocations in CSNs and CSRs, the dislocations densities at key points during the nanoindentation simulations were calculated. Fig. 16 shows the calculated dislocations densities at maximum indenter displacement, immediately after the indenter loses contact with the nanostructure during unloading, and at equilibrium (at least 85,000 time steps after the indenter has lost contact with the nanostructure). For the $\mathrm{CSN}$, which is the structure with the most highly confined core, approximately $65 \%$ of the dislocations nucleated during indentation are removed when the structure is fully unloaded and further increases to $93 \%$ at equilibrium. When this confinement is reduced, as in the CSRs, the dislocation density relaxes to a nearly constant value when fully unloaded, regardless of core length, with minimal additional recovery occurring at equilibrium. For these structures, the proportion of dislocations removed at equilibrium from the core of the CSRs decreases from $89 \%$ to $85 \%$ and then to $83 \%$ as the core length increases from $15 \mathrm{~nm}$ to 25 $\mathrm{nm}$ and $35 \mathrm{~nm}$, respectively. The reduced lateral confinement exhibited in the CSRs allows more opportunity for dislocations to cross-slip or otherwise form sessile dislocations, such as Hirth or Stair-rod dislocations, resulting in less dislocation recovery compared to the CSN.

\section{Conclusions}


Nanoindentation experiments were performed on several different geometries of $\mathrm{Al} / \mathrm{a}-\mathrm{Si}$ nanostructures, including hemispherical CSNs, horizontally-aligned CSRs, and a layered thin film, to investigate the effects of geometrical confinement of the Al core on the CSN deformation behavior. The CSNs have deformation-resistant properties, as indicated by complete recovery of deformation beyond the elastic limit. When the core confinement is slightly reduced, the deformation resistance that is observed in the CSNs is substantially reduced. A further reduction in core confinement results in more conventional indentation behavior regardless of geometry. Supporting molecular dynamics simulations show that dislocations nucleated in the core of CSNs are more readily removed during unloading compared to CSRs, which indicates that the 3-dimensional core confinement of the CSNs plays an important role in the deformation resistant properties of CSNs. This study elucidates the effects that core confinement plays on the novel nanoindentation behavior of hemispherical Al/a-Si CSNs, which will allow for the rational design and effective implementation of these structures in nanomechanical applications. 


\section{Acknowledgments}

Funding support for this work was provided by the US National Science Foundation (NSF) under Grant Nos. CMS-1463306, DGE-0957325, and partial support from the Center for Advanced Surface Engineering under Grant No. OIA-1457888 and the Arkansas EPSCoR Program, ASSET III. We thank the Arkansas Biosciences Institute and the University of Arkansas for major equipment funding support, as well as the Arkansas Nano \& Bio Materials Characterization Facility and the High Density Electronics Center for equipment use. This work used the Extreme Science and Engineering Discovery Environment (XSEDE), which is supported by NSF Grant No. ACI-1053575, as well as the Arkansas High Performance Computing Center, under NSF Grant Nos. ARI-0963249, MRI-0959124, and EPS-0918970. We

would also like to thank Dr. Douglas Spearot from the University of Florida Department of Mechanical \& Aerospace Engineering for helpful discussions about the molecular dynamics modeling in this work. 


\section{REFERENCES:}

[1] K.E. Aifantis, A.A. Konstantinidis, Hall-Petch revisited at the nanoscale, Mater. Sci. Eng. B. 163 (2009) 139-144.

[2] R.W. Armstrong, 60 years of hall-petch: Past to present nano-scale connections, Mater. Trans. 55 (2014) 2-12.

[3] C.S. Pande, K.P. Cooper, Nanomechanics of Hall-Petch relationship in nanocrystalline materials, Prog. Mater. Sci. 54 (2009) 689-706.

[4] S. Chang, A.K. Nair, M.J. Buehler, Nanoindentation study of size effects in nickel-graphene nanocomposites, Philosophical Magazine Letters. 93 (2013) 196-203.

[5] F. Hammami, Y. Kulkarni, Size effects in twinned nanopillars, J. Appl. Phys. 116 (2014).

[6] A.T. Jennings, J.R. Greer, Heterogeneous dislocation nucleation from surfaces and interfaces as governing plasticity mechanism in nanoscale metals, J. Mater. Res. 26 (2011) 2803-2814.

[7] W.D. Nix, J.R. Greer, G. Feng, E.T. Lilleodden, Deformation at the nanometer and micrometer length scales: Effects of strain gradients and dislocation starvation, Thin Solid Films. 515 (2007) 3152-3157.

[8] K.J. Hemker, W.D. Nix, Nanoscale deformation: Seeing is believing, Nature Materials. 7 (2008) 97-98.

[9] Z.W. Shan, R.K. Mishra, S.A. Syed Asif, O.L. Warren, A.M. Minor, Mechanical annealing and source-limited deformation in submicrometre- diameter Nicrystals, Nature Materials. 7 (2008) 115-119.

[10] W.W. Gerberich, W.M. Mook, C.R. Perrey, C.B. Carter, M.I. Baskes, R. Mukherjee, A. Gidwani, J. Heberlein, P.H. McMurry, S.L. Girshick, Superhard silicon nanospheres, J. Mech. Phys. Solids. 51 (2003) 979-992.

[11] W.W. Gerberich, W.M. Mook, M.J. Cordill, C.B. Carter, C.R. Perrey, J.V. Heberlein, S.L. Girshick, Reverse plasticity in single crystal silicon nanospheres, Int. J. Plast. 21 (2005) 23912405.

[12] A. Rinaldi, M. Correa-Duarte, V. Salgueirino-Maceira, S. Licoccia, E. Traversa, A. DavilaIbanez, P. Peralta, K. Sieradzki, Elastic properties of hard cobalt boride composite nanoparticles, Acta Materialia. 58 (2010) 6474-6486.

[13] A. Rinaldi, S. Licoccia, E. Traversa, K. Sieradzki, P. Peralta, A. Davila-Ibanez, M. CorreaDuarte, V. Salgueirino, Radial inner morphology effects on the mechanical properties of amorphous composite cobalt boride nanoparticles, Journal of Physical Chemistry C. 114 (2010) 13451-13458. 
[14] S. Vlassov, B. Polyakov, L.M. Dorogin, M. Vahtrus, M. Mets, M. Antsov, R. Saar, A.E. Romanov, A. Lhmus, R. Lhmus, Shape restoration effect in Ag-SiO2 core-shell nanowires, Nano Letters. 14 (2014) 5201-5205.

[15] W. Tidwell, D. Scott, H. Wang, R. Fleming, M. Zou, Nanoindentation study of deformationresistant Al/a-Si core-shell nanostructures, Acta Materialia. 59 (2011) 6110-16.

[16] B.D. Morton, H. Wang, R.A. Fleming, M. Zou, Nanoscale Surface Engineering with Deformation-resistant Core-shell Nanostructures, Tribology Letters. 42 (2011) 51-8.

[17] D. Mordehai, M. Kazakevich, D.J. Srolovitz, E. Rabkin, Nanoindentation size effect in single-crystal nanoparticles and thin films: A comparative experimental and simulation study, Acta Materialia. 59 (2011) 2309-2321.

[18] O.L. Warren, S.A. Downs, T.J. Wyrobek, Challenges and interesting observations associated with feedback-controlled nanoindentation, Zeitschrift für Metallkunde. 95 (2004) 287296.

[19] J. Li, K.J. Van Vliet, T. Zhu, S. Yip, S. Suresh, Atomistic mechanisms governing elastic limit and incipient plasticity in crystals, Nature. 418 (2002) 307-310.

[20] T. Zhu, J. Li, K.J. Van Vliet, S. Ogata, S. Yip, S. Suresh, Predictive modeling of nanoindentation-induced homogeneous dislocation nucleation in copper, J. Mech. Phys. Solids. 52 (2004) 691-724.

[21] V. Domnich, Y. Gogotsi, S. Dub, Effect of phase transformations on the shape of the unloading curve in the nanoindentation of silicon, Appl. Phys. Lett. 76 (2000) 2214-2214.

[22] J.S. Field, M.V. Swain, R.D. Dukino, Determination of fracture toughness from the extra penetration produced by indentation-induced pop-in, J. Mater. Res. 18 (2003) 1412-1419.

[23] C. Han, C. Huang, B. Wu, J. Lin, The nanoindentation applied to predict the interface delamination for the C/amorphous Si composite film, J. Appl. Phys. 106 (2009) 083517.

[24] S. Plimpton, Fast Parallel Algorithms for Short-Range Molecular Dynamics, J. Comput. Phys. 517 (1995) 1-19.

[25] M.I. Baskes, Modified embedded-atom potentials for cubic materials and impurities, Phys Rev B Condens Matter. 46 (1992) 2727-2742.

[26] B. Jelinek, S. Groh, M.F. Horstemeyer, J. Houze, S.G. Kim, G.J. Wagner, A. Moitra, M.I. Baskes, Modified embedded atom method potential for $\mathrm{Al}, \mathrm{Si}, \mathrm{Mg}, \mathrm{Cu}$, and $\mathrm{Fe}$ alloys, Physical Review B: Condensed Matter \& Materials Physics. 85 (2012) 1-18.

[27] J. Custer, M.O. Thompson, D. Jacobson, J. Poate, S. Roorda, W. Sinke, F. Spaepen, Density of amorphous Si, Appl. Phys. Lett. 64 (1994) 437-439. 
[28] A. Stukowski, V.V. Bulatov, A. Arsenlis, Automated identification and indexing of dislocations in crystal interfaces, Modell Simul Mater Sci Eng. 20 (2012).

[29] A. Stukowski, Visualization and analysis of atomistic simulation data with OVITO-the Open Visualization Tool, Modell Simul Mater Sci Eng. 18 (2010). 


\section{LIST OF FIGURE CAPTIONS}

Fig. 1: Schematic of the nanorod geometry.

Fig. 2: Schematics of the three geometrical confinements: hemispherical core-shell (a), coreshell rod (b), and layered thin film (c).

Fig. 3: SEM micrographs of $100 \mathrm{~nm}$ diameter Al nanodots (a) and horizontally-aligned Al nanorods with lengths of $100 \mathrm{~nm}(\mathrm{~b}), 500 \mathrm{~nm}(\mathrm{c})$, and $10 \mu \mathrm{m}(\mathrm{d})$.

Fig. 4: SEM micrographs of CSNs (a) and CSRs with core lengths of $100 \mathrm{~nm}$ (b), $500 \mathrm{~nm}$ (c), and $10 \mu \mathrm{m}(\mathrm{d})$.

Fig. 5: AFM images of a CSN (a) and CSRs with core lengths of $100 \mathrm{~nm}$ (b), $500 \mathrm{~nm}$ (c), and 10 $\mu \mathrm{m}(\mathrm{d})$.

Fig. 6: Load-displacement curves for 20, 40, 60, and $80 \mathrm{~nm}$ indents on CSNs.

Fig. 7: Load-displacement curves for 4 repeated $80 \mathrm{~nm}$ indents on a CSN. The maximum contact load increases after each subsequent indent, indicating hardening behavior.

Fig. 8: High resolution SEM micrographs of FIB milled cross-sections of an unindented CSN (a) and a CSN after 4 sequential $1000 \mu \mathrm{N}$ indentations (b), showing no evidence of shell delamination or crack formation. The contact load here is much higher than the maximum contact load observed $(<550 \mu \mathrm{N})$ from the repeated $80 \mathrm{~nm}$ indents on a CSN in Fig. 7.

Fig. 9: Load-displacement curve for an $80 \mathrm{~nm}$ indent on a CSR with a $100 \mathrm{~nm}$ core length (a). The AFM image of the surface morphology of the CSR (b) clearly shows residual deformation after indentation.

Fig. 10: Load-displacement curves for 4 repeated $80 \mathrm{~nm}$ indents on a CSR with a $100 \mathrm{~nm}$ core length. The indentation signatures are heavily reduced compared to the CSNs. 
Fig. 11: Load-displacement curves for $80 \mathrm{~nm}$ indents on a CSN, CSRs with $100 \mathrm{~nm}, 500 \mathrm{~nm}$, and $10 \mu \mathrm{m}$ core lengths, and a layered thin film.

Fig. 12: SPM images of the surface morphology after $80 \mathrm{~nm}$ indents on a CSN (a), CSRs with $100 \mathrm{~nm}(\mathrm{~b}), 500 \mathrm{~nm}(\mathrm{c})$, and $10 \mu \mathrm{m}$ (d) core lengths, and a layered thin film (e).

Fig. 13: Plot of contact stiffness vs. indentation displacement for a CSN, CSRs with $100 \mathrm{~nm}$, $500 \mathrm{~nm}$, and $10 \mu \mathrm{m}$ core lengths, and a layered thin film.

Fig. 14: Schematic of the MD simulation domain used in the nanoindentation simulations.

Fig. 15: A snapshot of atomic distortion resulting from dislocations nucleated in the core of a CSN (a); a snapshot of the dislocation content within the core, showing cross-slipped dislocations (b); and the time evolution of dislocation egression and sessile dislocation structure formation during unloading (c).

Fig. 16: Dislocation densities calculated from MD nanoindentation simulations for a CSN with a $30 \mathrm{~nm}$ core diameter and CSRs with various core lengths. 
Figure 1

A 
(a)
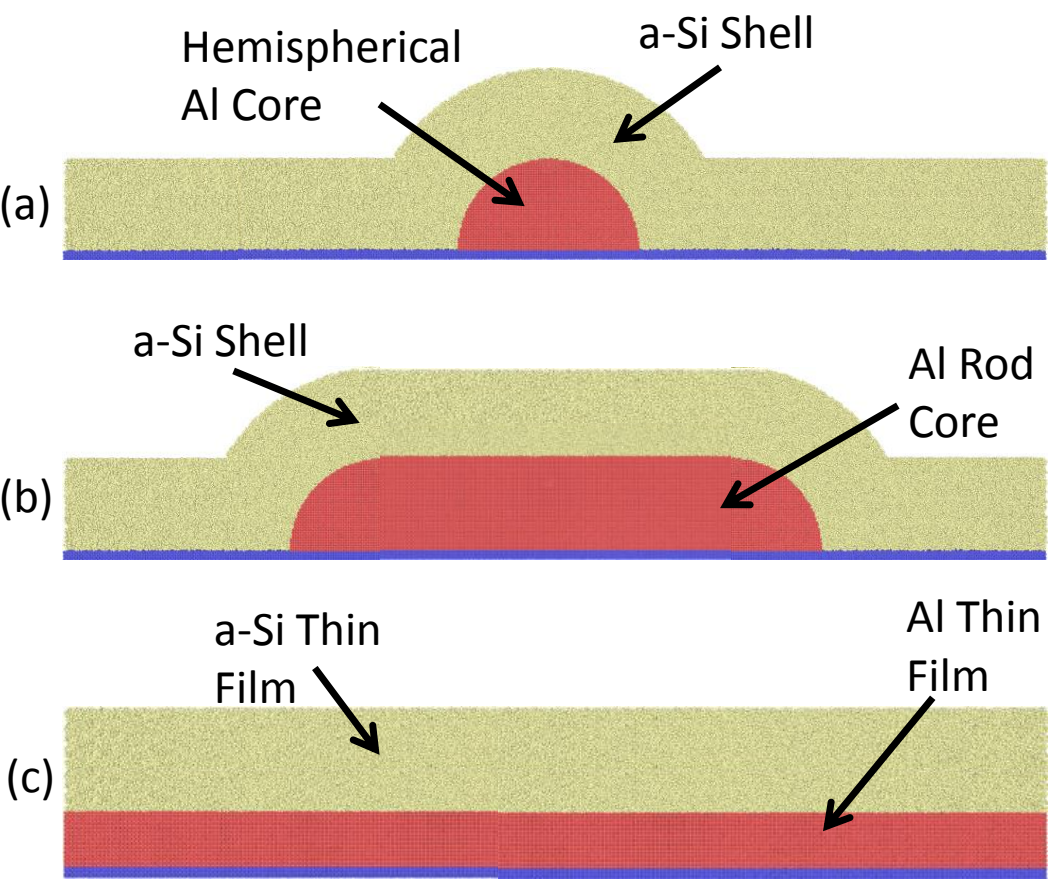
Figure 3
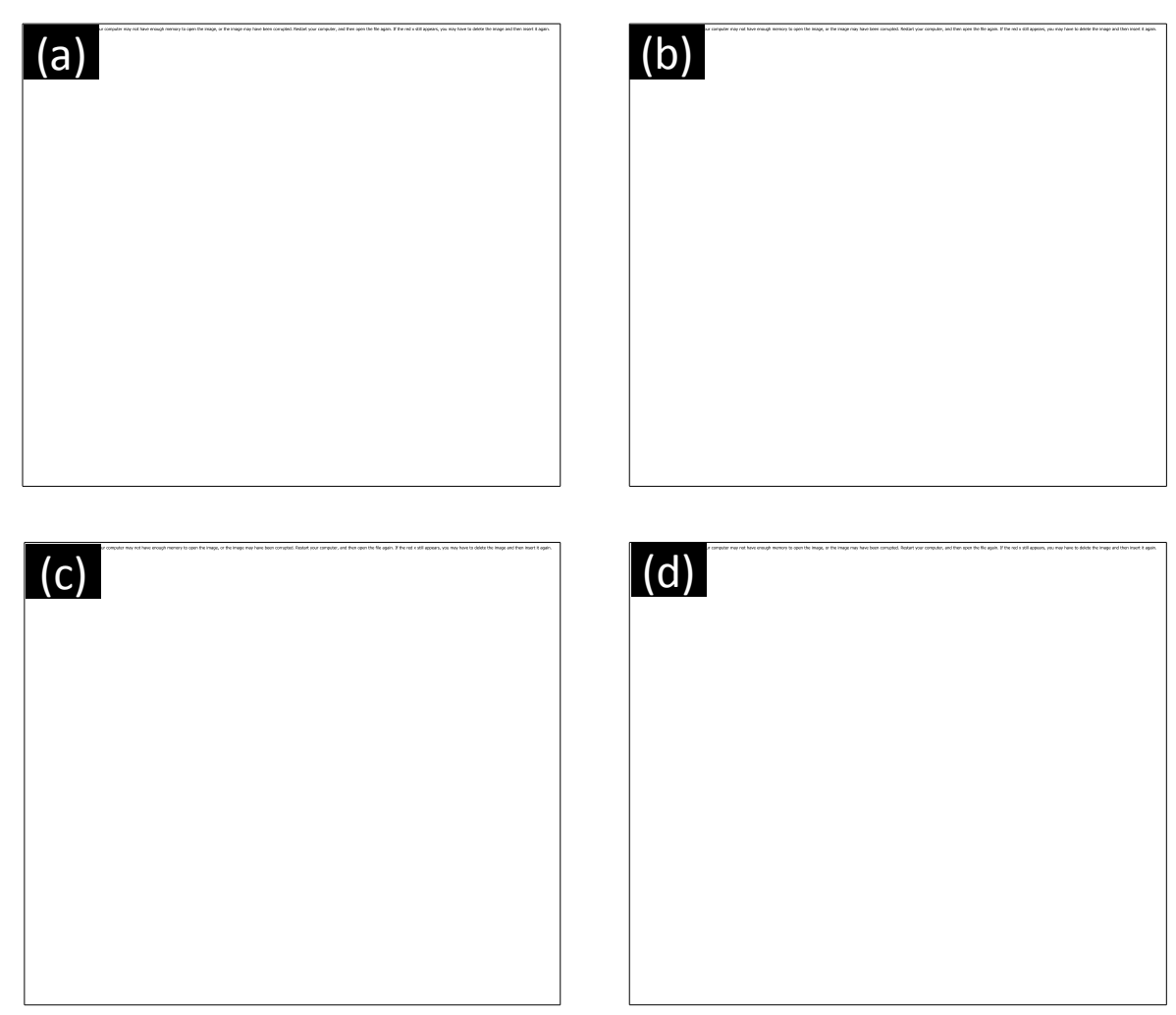

(d)
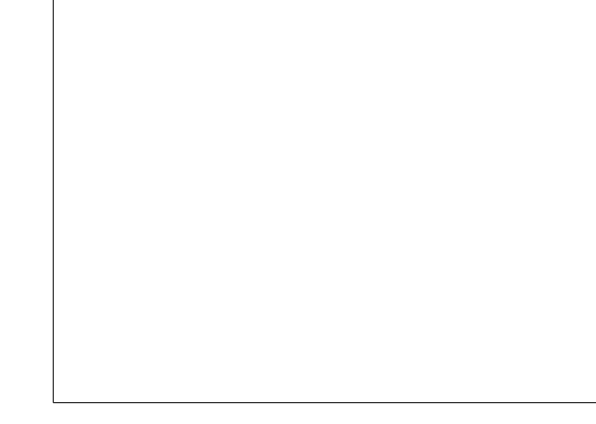


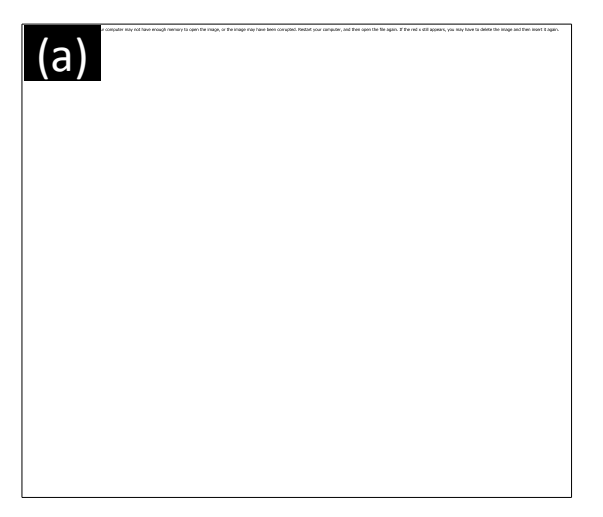

(b)

(c)

(d)

.

Figure 4
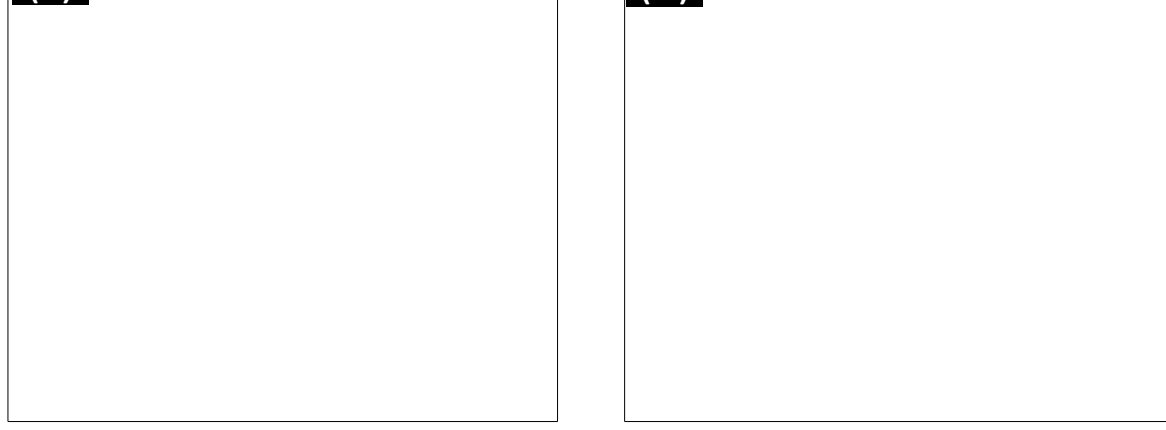
Figure 5
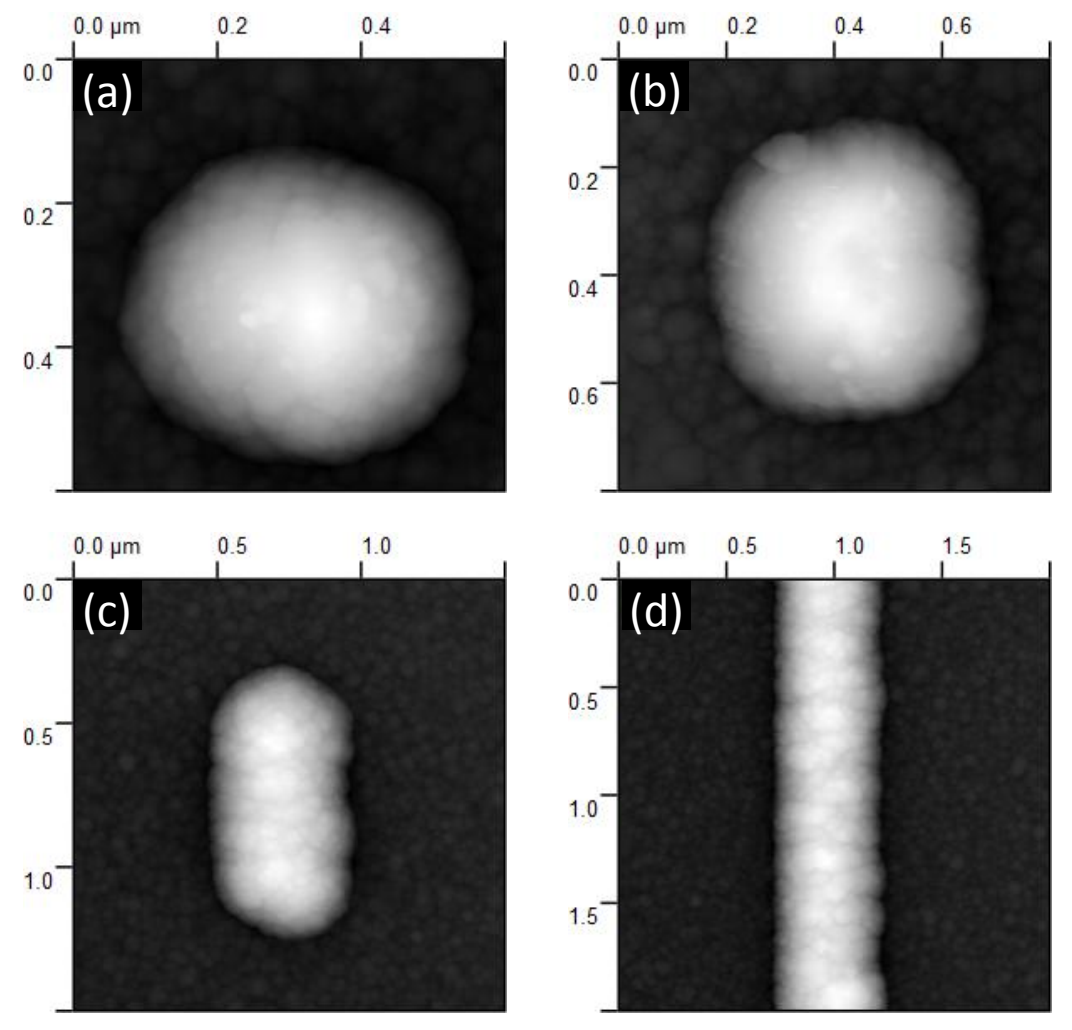

\section{Figure}


Figure 6

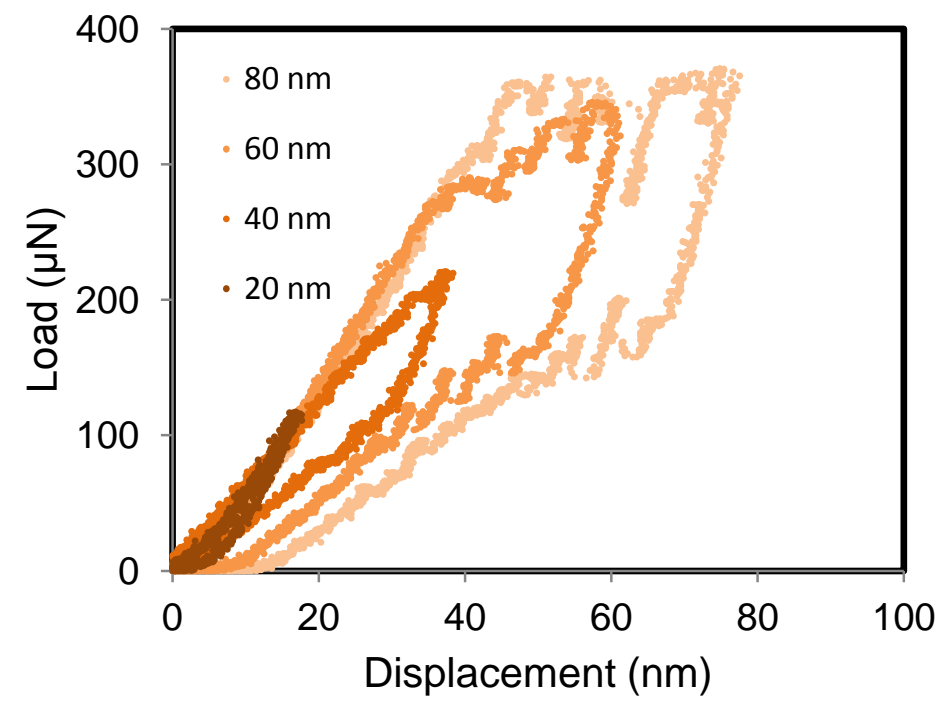


Figure 7

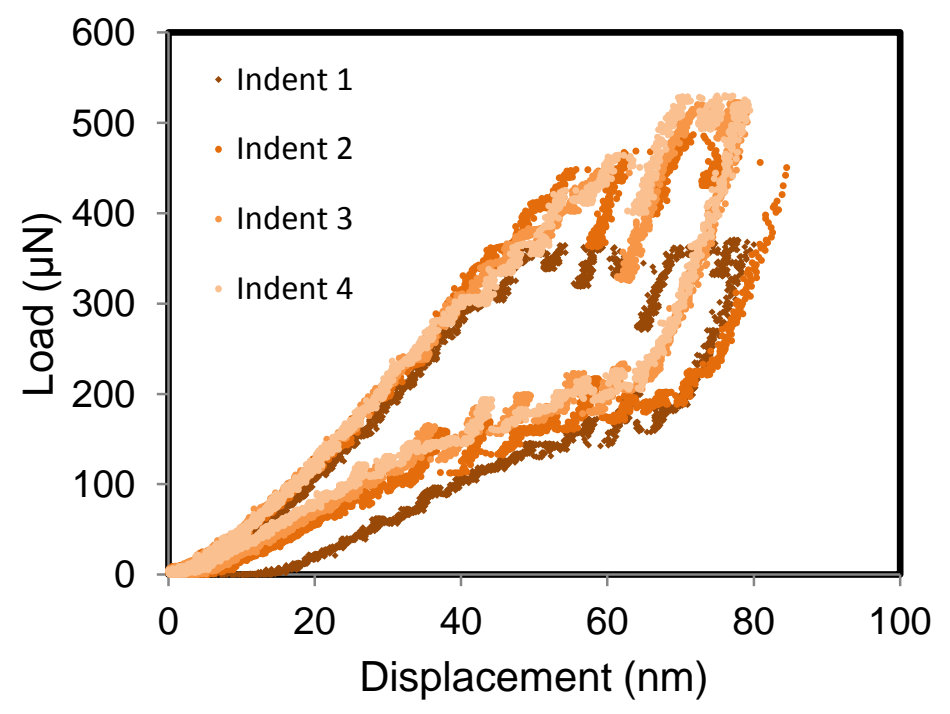


Figure 8

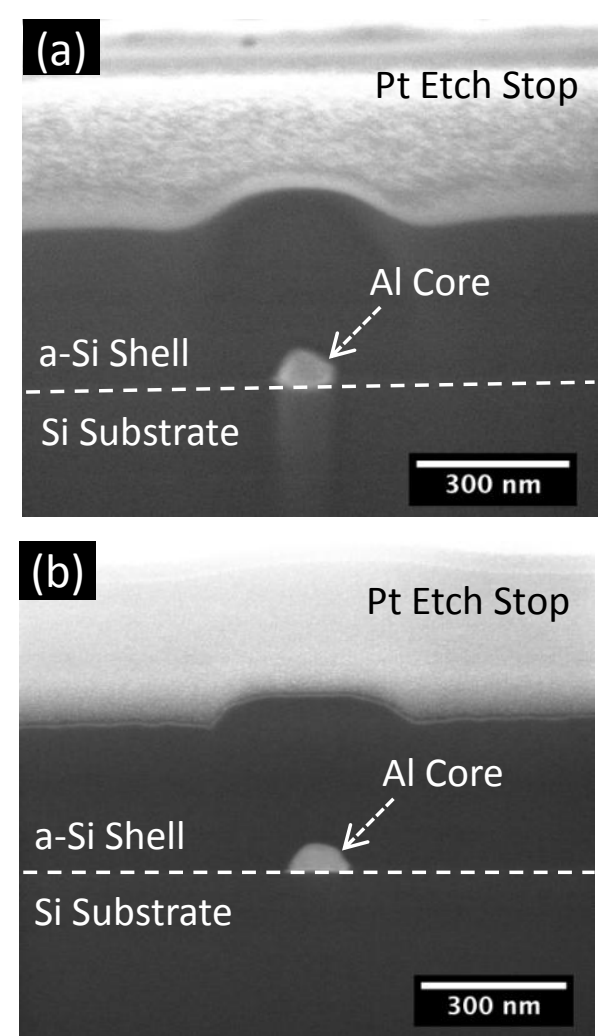




\section{Figure 9}

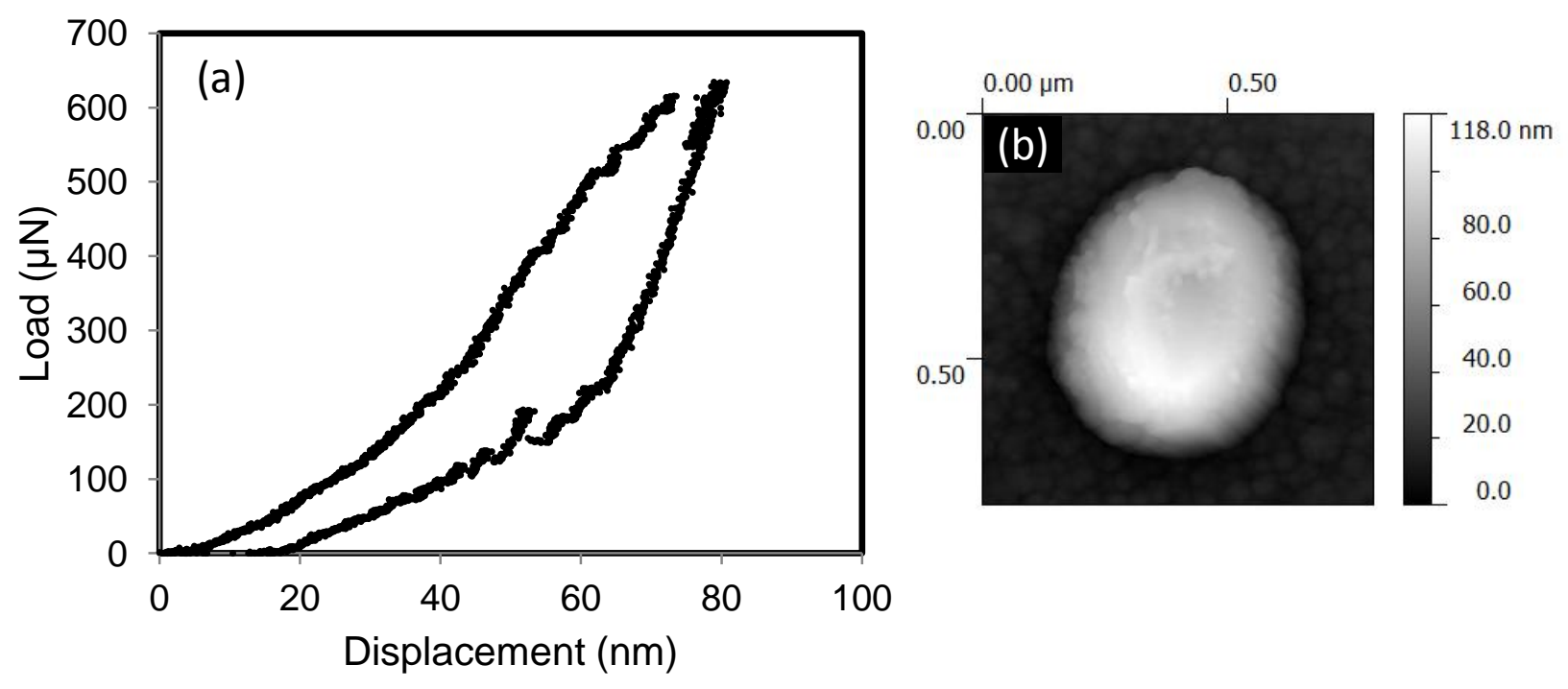


Figure 10

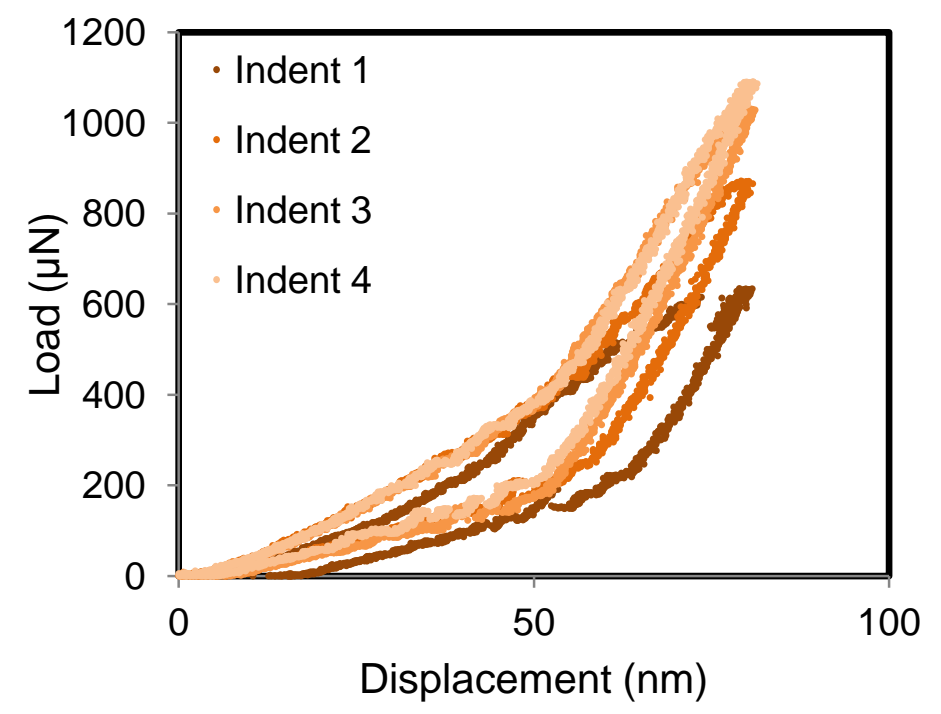


Figure 11

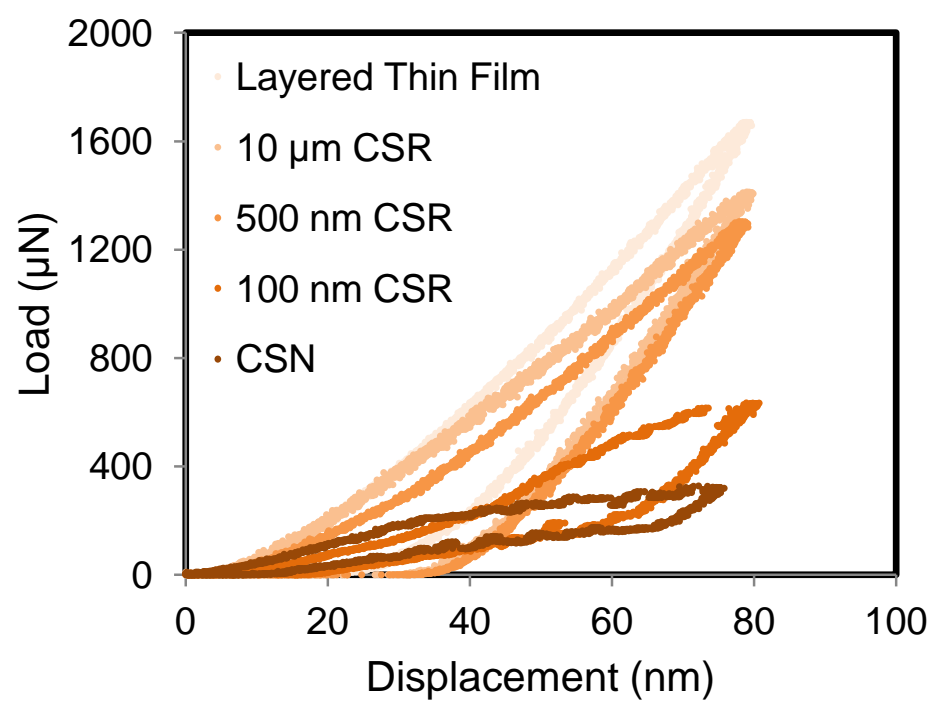



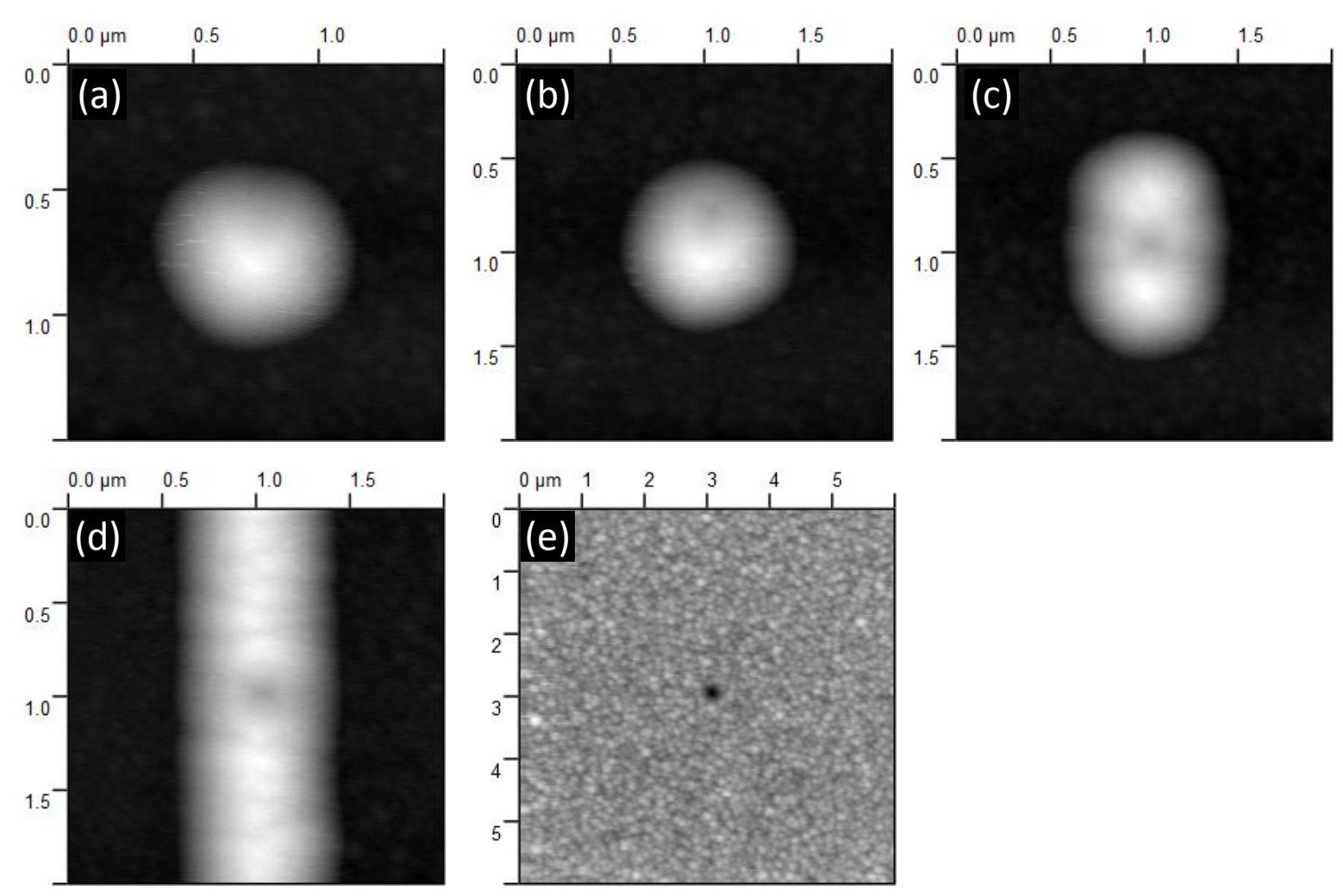

\section{Figure 12}




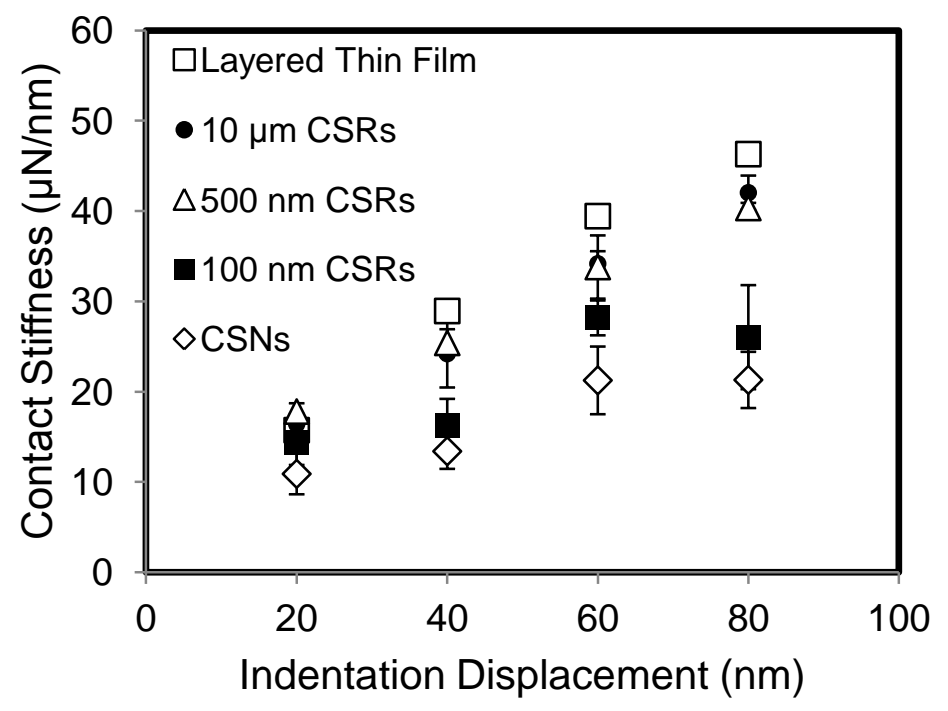


Spherical Indenter,

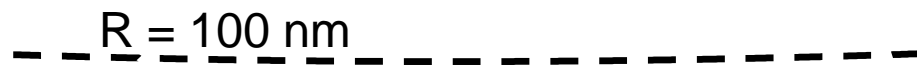

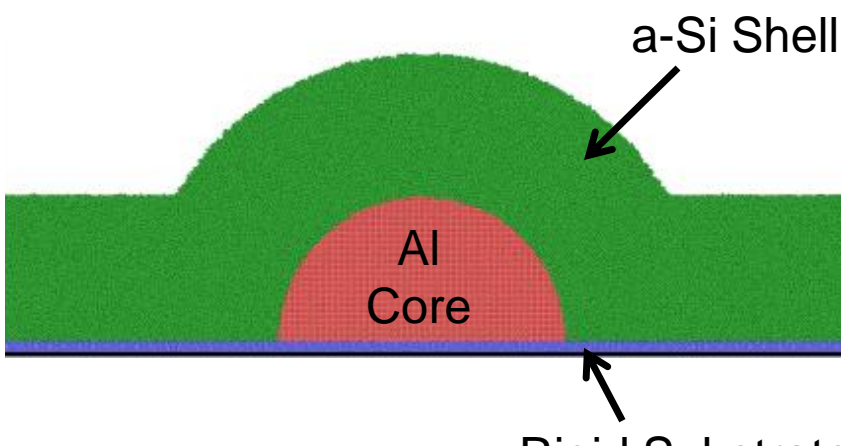

Rigid Substrate 
(a)

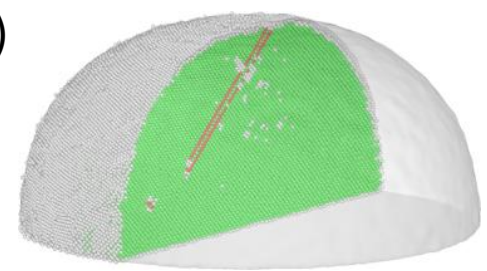

(b)

(c)

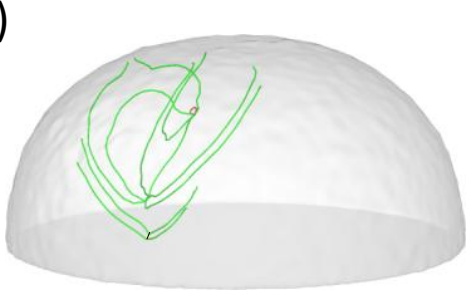

Maximum Indenter

Displacement

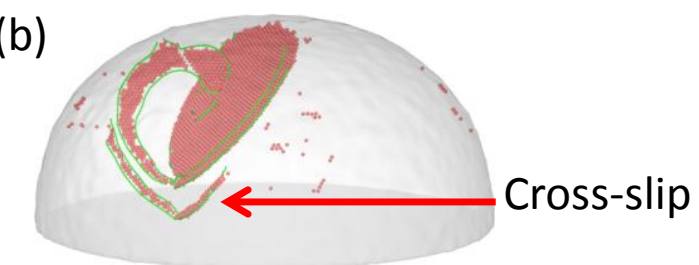

Sessile Dislocation

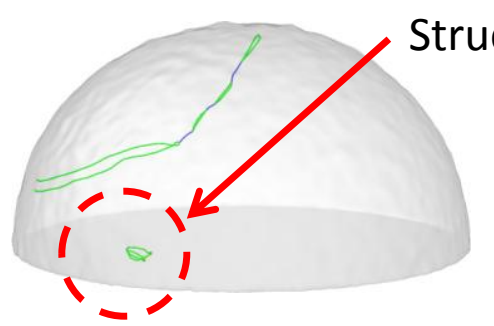

Fully Unloaded

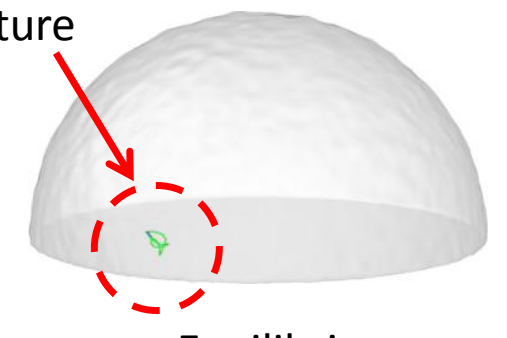

Equilibrium

Time 
- Maximum Indenter Displacement $\quad$ Fully Unloaded $₫$ Equilibrium

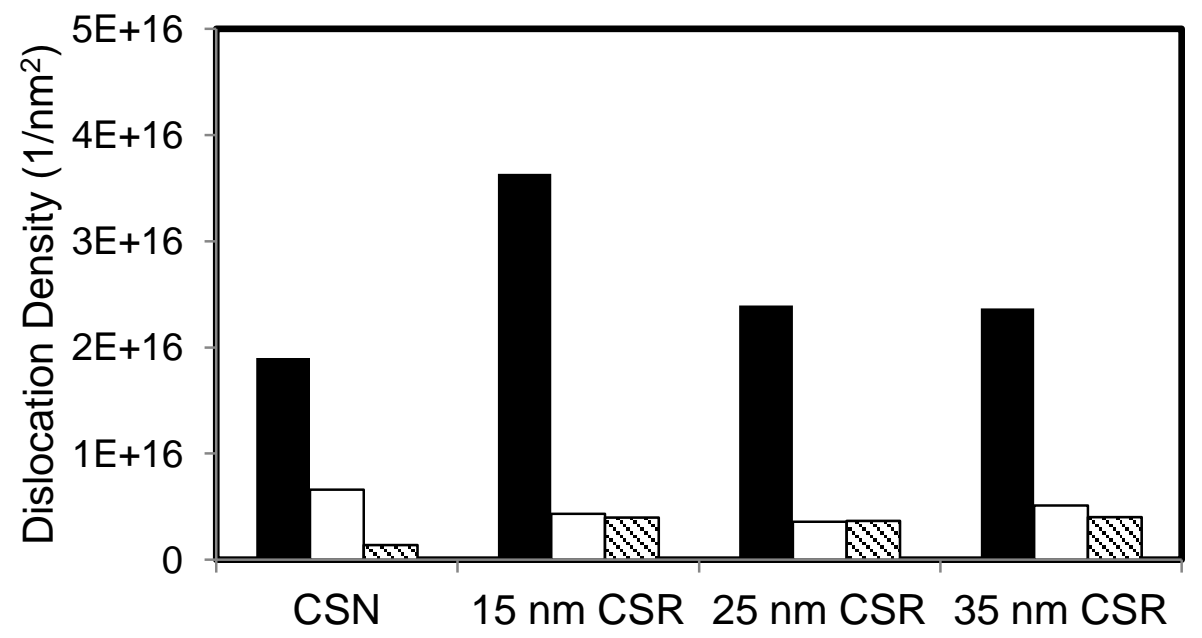


The "dimensionality" of core confinement greatly influences the mechanical behavior of $\mathrm{Al} / \mathrm{a}-\mathrm{Si}$ core-shell nanostructures

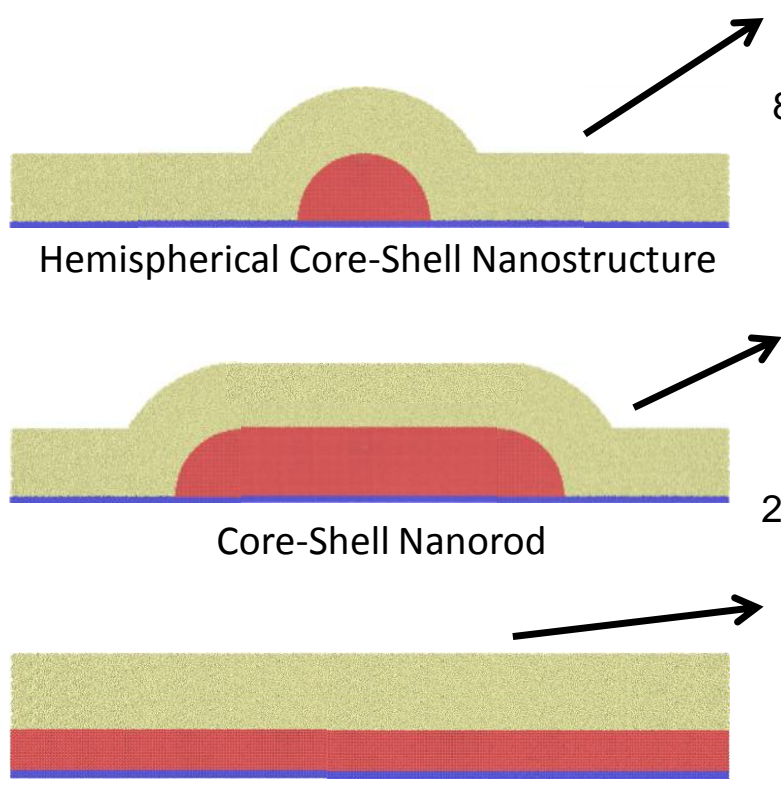

Layered Thin Film
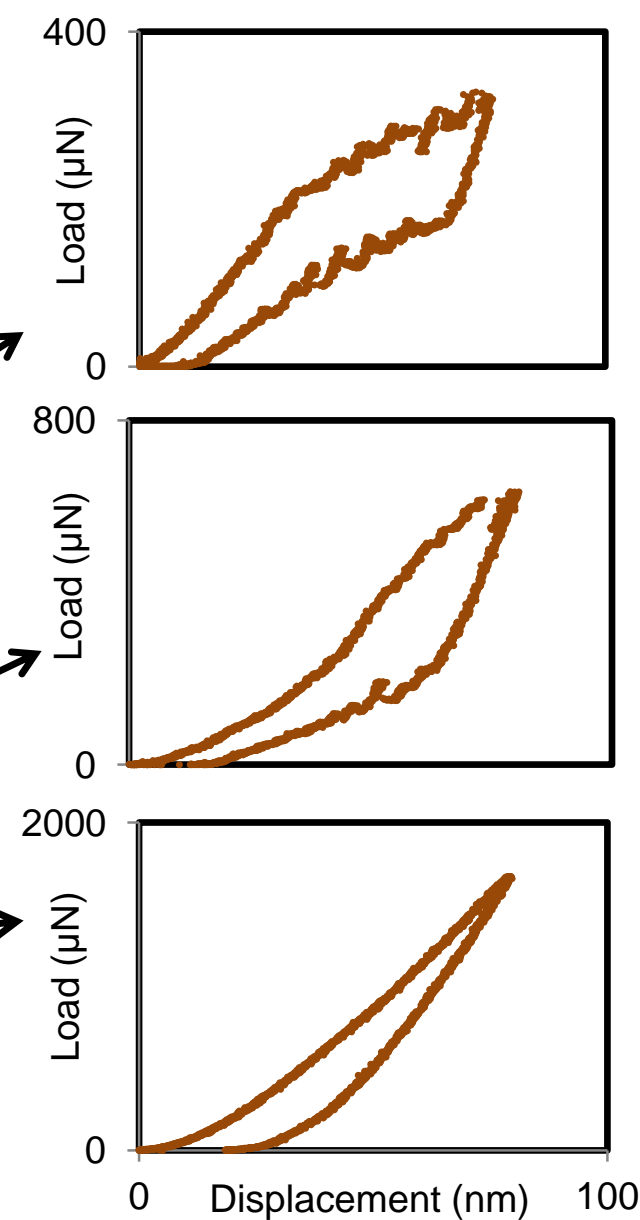